\title{
Students as Co-creators: the Development of Student Learning Networks in PeerWise
}

\author{
Judy Hardy, Alison E. Kay and Ross K. Galloway \\ Physics Education Research Group, School of Physics and Astronomy, \\ University of Edinburgh, Edinburgh, EH9 6JZ, UK
}

\begin{abstract}
PeerWise, an online tool that facilitates peer learning through student-generated content in the form of multiple-choice questions, was implemented in a large introductory university physics course. Interactions between students engaged in PeerWise were investigated using social network analysis. This showed that a dense and relatively equitable network was formed, giving students direct and easy access to the whole cohort through sharing and answering questions. A statistically significant correlation was found between students' use of PeerWise and their performance in the end-of-course examination, even after taking into account their prior ability as measured by assessment prior to the start of the course. This suggests that students benefit from engaging with their peers, not only by sharing or answering a large number of questions but perhaps by being exposed to a wide range of question styles, levels, explanations and comments.
\end{abstract}

Keywords: assessment, student-generated content, e-learning, social network analysis PACS: 01.40.-d, 01.40.G-, 01.40.Ha

\section{INTRODUCTION}

One of the key attributes that physics educators aim to inculcate in their students is the ability to solve advanced and complex problems. To this end, providing opportunities for students to develop their problem-solving skills forms a central part of all undergraduate physics curricula. In many tutorial and workshop classes there is an emphasis on collaborative learning; it is generally recognised that such activities promote a deep approach to learning as well as the development of problem-solving skills and other high level attributes such as self-reflection and communication skills [1,2]. However there is often relatively little support for out-of-class learning activities, although initiatives such as subject-based learning centres aim to foster both formal and informal collaborative learning in a face-to-face setting [3].

In many early years physics courses, coursework assessment takes the form of weekly problem sheets. While this 'tried and tested' approach is undoubtedly of value, there is evidence that deep learning can be fostered by asking students to write questions and the associated explanations, as well as answer them [4-6]. Furthermore, questioning is key to the scientific method and is an important tool in any problem solving activity $[5,7]$.

PeerWise $[8,9]$ is an online tool that enables students to write multiple-choice questions (MCQs) and associated explanations, share them with their peers, and answer, rate and comment on each other's questions; a pedagogy that has been described as 'constructive evaluation' [10]. Although MCQs are more commonly used for summative assessment, when set in an appropriate pedagogical framework they have been shown to support formative assessment and feedback as well as promoting autonomous learning $[11,12]$. The interactive design of PeerWise means that students have extensive opportunities to collaborate with their peers and to engage in both peer and selfassessment and feedback.

Correlation between PeerWise use and learning gains has been reported in courses in a number of disciplines, including computer science $[9,13]$ and physics [14]. The latter study also stresses the need for appropriate 'scaffolding' by encouraging students to create and share cognitively demanding questions that are at the limit of their current level of understanding. In effect, students are working in their 'zone of proximal development' [15] and are hence well-placed both to benefit from the assistance of more able peers and to give advice and support to others.

However, little work has been done to date to investigate interactions between students and the networks that form through use of PeerWise, despite the fact that such interactions are one of the cornerstones of the system; PeerWise enables students to interact with the whole cohort by answering, rating and commenting on questions set by other students. Furthermore, it is completely anonymous. It seems 
likely, therefore, that participation in PeerWise would encourage students to engage with a much wider range of people than they would face-to-face, and that such interactions would be equitable i.e. not bound by the social groupings that develop in the 'real world'.

The development of student learning communities in an informal face-to-face setting (a physics learning centre) has been studied using the tools of social network analysis [3,16]. In this paper we report on work done using a similar approach to explore interactions between students using the PeerWise system in an introductory undergraduate physics course. To the best of our knowledge, this is the first time that a social network analysis of PeerWise interactions has been reported. We also report the connection between students' engagement with PeerWise and their overall course performance.

\section{IMPLEMENTATION}

PeerWise was implemented in a mainstream first year course on Newtonian mechanics taught at the University of Edinburgh during 2012/13. 282 students took the course; approximately half were registered for a physics degree, with the remainder taking other degrees, mainly but not exclusively in science subjects. PeerWise implementation details for the course have been described elsewhere [14]; in summary, the rationale for and pedagogical benefits of the activity were introduced to students in an orientation workshop, with additional supporting resources made available online. Students were able to use PeerWise from the orientation workshop to the end of the course, however there was a minimum requirement in terms of the number, type and timing of PeerWise activities, see Table 1. Students' PeerWise activities counted for $4 \%$ of the final course mark.

TABLE 1. Required PeerWise activities

\begin{tabular}{ll} 
Number of participation deadlines & 2 \\
Minimum contribution per deadline: & \\
Number of questions authored & 1 \\
Number of questions answered & 5 \\
Rate \& comment on questions & 3 \\
\hline
\end{tabular}

At the end of the course the following measures of PeerWise activity were collected for each student:

- Questions authored

- Questions answered

- Questions commented on

- Average character count for all comments posted

- Total number of days of PeerWise activity

The average character count was used rather than the number of comments posted, as inspection showed that many short comments were little more than pleasantries, while longer comments showed clear evidence of engagement with the question.

Force Concept Inventory (FCI) [17] pre- and posttest marks and end-of-course examination marks were also collected for each student, together with basic demographic information.

The lists of questions authored, answered and commented on for each student were used to construct a rectangular matrix comprising students (rows) and questions (columns), with the value of each matrix element corresponding to whether a student had answered a question (1), had answered and commented on it (2) or had not answered it (0). Note that in PeerWise it is not possible to comment on a question without having first answered it. This matrix was then used to construct a 2-mode (student and question) network using the social network analysis package UCINET [18]. From this, two 1-mode student networks were constructed; one in which connections between students indicate that they had answered the same question(s), and one where connections indicate that they had commented on the same question(s). In the following sections, these networks are called the answer and comment networks respectively.

Network visualisations were created using the software package NETDRAW [19]. Statistical tests were performed using the statistical software package SPSS (activity data) and UCINET (network data).

\section{STUDENT ENGAGEMENT AND PERFORMANCE}

The overall level of PeerWise activity at the end of the course is summarised in Table 2. It is evident that most students contributed more than the minimum requirements (see Table 1), with some contributing significantly more than this.

TABLE 2. Summary of student PeerWise activities

\begin{tabular}{lrrr}
\hline & Median & Mean & Max \\
\hline $\begin{array}{l}\text { Number of questions } \\
\text { authored }\end{array}$ & 2 & 2.4 & 11 \\
$\begin{array}{l}\text { Number of questions } \\
\text { answered }\end{array}$ & 17 & 25.8 & 256 \\
$\begin{array}{l}\text { Average comment } \\
\text { length (characters) }\end{array}$ & 82 & 104.4 & 538 \\
$\begin{array}{l}\text { Number of days of } \\
\text { activity }\end{array}$ & 4 & 5.1 & 23 \\
\hline
\end{tabular}

In order to identify any association between student use of PeerWise and their performance at the end of the course, it is important to take into account students' ability in the subject before PeerWise is introduced. We used the pre-test FCI mark as a measure of prior ability; Table 3 shows the results of a partial correlation conducted between each PeerWise activity 
and the end-of-course exam mark, controlling for the pre-test FCI mark. Our hypothesis was directional, i.e. that a greater level of PeerWise activity would result in a higher exam mark, hence a one-tailed test was used.

TABLE 3. Spearman partial correlation $r_{s}$ between PeerWise activities and end-of-course exam mark, controlling for pre-course FCI mark

\begin{tabular}{lccc}
\hline & $\boldsymbol{N}^{\mathrm{a}}$ & $\boldsymbol{r}_{\boldsymbol{s}}$ & $\boldsymbol{p}^{\mathrm{b}}$ \\
\hline $\begin{array}{l}\text { Number of questions } \\
\text { authored }\end{array}$ & 247 & 0.24 & 0.000 \\
$\begin{array}{l}\text { Number of questions } \\
\text { answered }\end{array}$ & 247 & 0.24 & 0.000 \\
$\begin{array}{l}\text { Average comment } \\
\text { length }\end{array}$ & 243 & 0.22 & 0.001 \\
$\begin{array}{l}\text { Number of days of } \\
\text { activity }\end{array}$ & 247 & 0.33 & 0.000 \\
\hline
\end{tabular}

${ }^{a}$ Excludes students who did not take the pre-course FCI or did not use PeerWise. All students who used PeerWise both authored and answered questions, but not all students commented on questions, hence the variation in $N$.

${ }^{\mathrm{b}}$ One-tailed value.

Although the effect $r_{s}$ is small, it is significant for every activity measure. This provides evidence for a positive correlation between PeerWise activity and performance as measured by the end-of-course exam mark, even after taking students' prior ability into account.

\section{ONLINE STUDENT NETWORKS}

Summary statistics for the student answer and comment networks, as described above, are shown in Table 4.

TABLE 4. Connectivity measures for 1-mode networks

\begin{tabular}{lrr}
\hline & $\begin{array}{r}\text { Answer } \\
\text { network }^{\mathrm{a}}\end{array}$ & $\begin{array}{r}\text { Comment }_{\text {network }^{\mathrm{a}}} \\
\hline \begin{array}{l}\text { Number of nodes } \\
\text { (students) }\end{array}\end{array}$ \\
$\begin{array}{l}\text { Network density } \\
\begin{array}{l}\text { Average degree } \\
\text { centrality }\end{array}\end{array}$ & 276 \\
$\begin{array}{l}\text { Average normalised } \\
\text { degree centrality }\end{array}$ & 0.565 & 0.275 \\
\hline $\begin{array}{l}\mathrm{a} \text { Excludes isolates i.e. students with no connections to } \\
\text { another student. }\end{array}$ & 155.4 & 74.1 \\
\end{tabular}

The network density is the number of connections between students divided by the number of possible connections. The answer network in particular is rather dense, with many students being connected i.e. having answered the same questions. This is illustrated very clearly in Fig. 1, which shows the answer network for all students who used PeerWise.

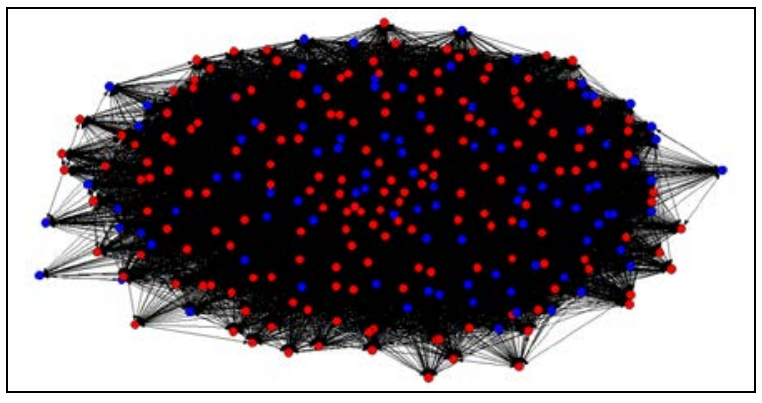

FIGURE 1. 1 mode answer network. A connection between nodes (students) indicates that they answered at least one common question. Colours represent physics majors (blue) and non-majors (red).

An example of the connections to a single student (i.e. that student's ego network) is shown in Fig. 2. This illustrates the number and complexity of connections that form between students in this online environment, which are significantly larger than those formed in face-to-face settings. ${ }^{16}$

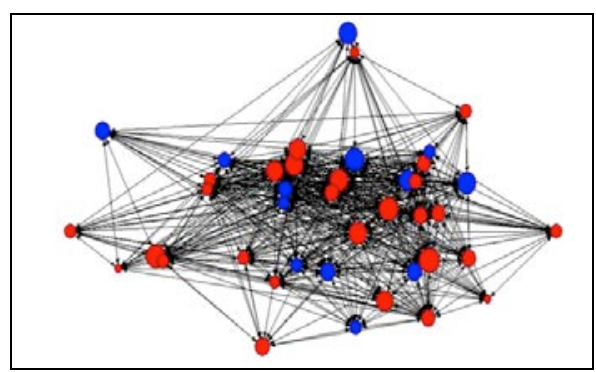

FIGURE 2. Ego comment network for medium-performing student (exam mark $=68 \%$; class average exam mark=67 $\pm 16 \%$ ). Nodes (students) are sized by attainment on end-of-course exam. Colours represent physics majors (blue) and non-majors (red).

Centrality is an important concept in social network analysis, as it relates to the relative 'importance' of a particular node within the network [20]. There are many interpretations of centrality, but they all provide a measure of prominence or influence in a given network. In this study we have used degree centrality, which is given by the number of connections to a node. Degree centrality is thus a measure of how 'wellconnected' a node (i.e. student) is; it is appropriate in our context as it can be interpreted as a measure of the extent of collaboration between students $[3,20]$. The normalised degree centrality is given by the degree centrality divided by the number of possible connections.

A partial correlation was performed between the normalised degree centrality and the end-of-course exam mark, controlling for pre-FCI mark, see Table 5. A bootstrapped approach was used, as standard 
statistical tests cannot normally be applied to social network data. This is because such tests are based on the assumption that observations are independent, however this is not the case for network data, which are not independent. Our hypothesis was that a higher degree centrality would infer a higher exam mark hence a one-tailed test was used.

TABLE 5. Partial correlation $r$ between student network normalised degree centrality and end-of-course exam mark, controlling for pre-course FCI mark.

\begin{tabular}{ccc}
\hline & $\boldsymbol{r}^{\mathrm{a}}$ & $\boldsymbol{p}^{\mathbf{b}}$ \\
\hline $\begin{array}{c}\text { Answer } \\
\text { network } \\
\text { Comment } \\
\text { network }\end{array}$ & 0.12 & 0.02 \\
\hline
\end{tabular}

${ }^{\mathrm{a}}$ Bootstrapped using 1,000 samples.

${ }^{\mathrm{b}}$ One-tailed value.

The effect size is small, albeit statistically significant, for both the answer and comment networks. Taken at face value this suggests, perhaps surprisingly, that interactions between students have little effect on their performance. However it should be emphasised that these networks represent a rather indirect and shallow form of collaboration, i.e. answering or commenting on common questions; other metrics may reveal more significant effects.

\section{CONCLUSIONS}

PeerWise was implemented in an introductory course in Newtonian mechanics at the University of Edinburgh. A statistically significant correlation was found between engagement with PeerWise (authoring questions, answering questions or commenting on questions) and performance in the end-of-course exam, even taking prior ability into account (as measured by the pre-course FCI mark). These findings are consistent with those reported in an earlier study at our institution [14]. A similar correlation was found between the number of days of PeerWise activity and exam performance. This suggests that the importance of time on task should not be underestimated, irrespective of the details. Hence, whatever requirements are placed on students in terms of the number and type of PeerWise activities, they should be designed to facilitate sustained engagement, for example by setting intermediate deadlines or by encouraging students to revise questions in response to comments from their peers.

Social network analysis shows promise as a tool for investigating the nature of the online networks that form between students using PeerWise. Initial results indicate that these networks are dense and relatively equitable, giving students access to the whole cohort and hence exposing them to a wide range of question styles, levels and topics posed by their peers. Although preliminary results show little evidence that 'indirect' collaboration between students (as measured by answering or commenting on the same questions) affects performance, this is a fruitful area for further research. One particular area of interest is the network formed from direct collaborations between question authors and question commenters. It would also be interesting to expand this to take account of the quality of student interactions.

\section{REFERENCES}

1. D. Boud, R. Cohen, and J. Sampson, Assessment \& Evaluation in Higher Education 24, 413 (1999).

2. K.J. Topping, Educational Psychology 25, 631 (2005).

3. E. Brewe, L. Kramer, and V. Sawtelle, Physical Review Special Topics - Physics Education Research 8, 010101 (2012).

4. B. Rosenshine, C. Meister, and S. Chapman, Review of Educational Research 66, 181 (1996).

5. C. Chin and D.E. Brown, International Journal of Science Education 24, 521 (2002).

6. S.W. Draper, British Journal of Educational Technology 40, 285 (2009).

7. U. Zoller, Journal of Chemical Education 510 (1987).

8. P. Denny, A. Luxton-Reilly, and J. Hamer, in Proceedings of the Tenth Conference on Australasian Computing Education - Volume 78 (Australian Computer Society, Inc., Darlinghurst, Australia, Australia, 2008), pp. 69-74.

9. P. Denny, J. Hamer, A. Luxton-Reilly, and H. Purchase, in Proceedings of the Fourth International Workshop on Computing Education Research (ACM, New York, NY, USA, 2008), pp. 51-58.

10. A. Luxton-Reilly and P. Denny, Computer Science Education 20, 145 (2010).

11. D.J. Nicol and D. Macfarlane-Dick, Studies in Higher Education 31, 199 (2006).

12. D. Nicol, Journal of Further and Higher Education 31, 53 (2007).

13. P. Denny, B. Hanks, and B. Simon, in Proceedings of the 41st ACM Technical Symposium on Computer Science Education (ACM, New York, NY, USA, 2010), pp. 421-425.

14. S.P. Bates, R.K. Galloway, and K.L. McBride, AIP Conference Proceedings 1413, 123 (2012).

15. L. Vygotsky, in Readings on the Development of Children (Harvard University Press, 1978), pp. 79-91.

16. E. Brewe, L.H. Kramer, G.E. O’Brien, C. Singh, M. Sabella, and S. Rebello, AIP Conference Proceedings 1289, 85 (2010).

17. D. Hestenes, M. Wells, and G. Swackhamer, The Physics Teacher 30, 141 (1992).

18. L.C. Borgatti, S.P., Everett, M.C., Freeman, (2002).

19. S.P. Borgatti, (2002).

20. S. Wasserman and K. Faust, Social Network Analysis: Methods and Applications (Cambridge university press, 1994). 